\title{
Efeito de óleos essenciais como alternativa no controle de Colletotrichum gloeosporioides, em pimenta.
}

\author{
Rosa Maria Souto de Sousa ${ }^{1}$; Ilka Marcia Ribeiro de Souza Serra ${ }^{2}$, Thiago Anchieta de Melo ${ }^{1}$
}

${ }^{1}$ Graduando do Curso de Agronomia, Universidade Estadual do Maranhão, UEMA, CEP 65041-970, São Luís, MA; ${ }^{2}$ Departamento de Fitotecnia e Fitossanidade, Universidade Estadual do Maranhão, UEMA, CEP 65041-970, São Luís, MA;

Autor para correspondência: Ilka Marcia R. de Souza Serra (ilka.tt@gmail.com)

Data de chegada: 30/05/2001. Aceito para publicação em: 13/02/2012.

\section{RESUMO}

Sousa, R.M.S; Serra, I.M.R.S; Melo, T.A. Efeito de óleos essenciais como alternativa no controle de Colletotrichum gloeosporioides, em pimenta. Summa Phytopathologica, v.38, n.1, p.42-47, 2012.

Fungos do gênero Colletotrichum causam doenças conhecidas como antracnose. Métodos alternativos que sejam eficientes e menos agressivos vêm sendo amplamente testados. Dentre estes, surge o interesse pela utilização de óleos essenciais extraídos de vegetais. O presente trabalho teve como objetivo avaliar o efeito de óleos essenciais de eucalipto, copaíba, andiroba, babaçu, coco, neem, semente de uva, amêndoa, hortelã e pau rosa, em diferentes concentrações sobre o fungo Colletotrichum gloeosporioides, in vitro e em frutos de pimenta em pós colheita. O experimento in vitro foi realizado utilizando-se cinco concentrações $(0,2 ; 0,4 ; 0,6 ; 0,8$ e $1,0 \%)$ dos dez óleos misturados ao meio de cultura BDA. As variáveis analisadas foram a taxa de crescimento micelial e o índice de velocidade de crescimento micelial (IVCM). O ensaio em pós-colheita foi feito com imersão dos frutos de pimenta por 5 minutos, nos mesmos óleos utilizados no experimento anterior, usando-se a maior concentração.
O fungo C. gloeosporioides foi inoculado, através de ferimento, logo após a imersão dos frutos. As avaliações foram realizadas diariamente através de medição do diâmetro das colônias e das lesões, tomando-se duas medições em sentidos diametralmente opostos. Pode-se observar que no experimento in vitro todos os óleos, com exceção dos óleos de babaçu, semente de uva e amêndoa, tiveram excelentes resultados inibindo o crescimento do fungo. No resultado obtido em pós-colheita foi observado que apenas o óleo de babaçu não foi eficiente em reduzir o desenvolvimento da lesão de antracnose. Dados relevantes foram observados para os óleos de semente de uva e amêndoa, que não apresentaram efeito direto sobre o fungo in vitro, porém no tratamento pós-colheita apresentaram bons resultados, reduzindo a lesão causada por C. gloeosporioides, sugerindo assim que estes óleos possam ser utilizados como indutores de resistência em frutos de pimenta com antracnose.

Palavras-chave adicionais: efeito fungitóxico; indução de resistência; antracnose.

\begin{abstract}
Sousa, R.M.S; Serra, I.M.R.S; Melo, T.A. Effect of essential oils as an alternative in the control of Colletotrichum gloesporioides in pepper. Summa Phytopathologica, v.38, n.1, p.42-47, 2012.

Colletotrichum spp. causes the disease known as anthracnose. Alternative methods that are efficient and less aggressive have been widely tested. Among these, there is interest in the scientific community by the use of essential oils extracted from plants. The subject of the present study was to evaluate the effect of essential oils eucalyptus, copaiba, andiroba, babassu, coconut, neem, grape seed, almond, mint and pau rosa in different concentrations on the development of Colletotrichum gloeosporioides, "in vitro" and in fruits of pepper in post harvest. The experiment in vitro was performed using five concentrations $(0.2,0.4,0.6,0.8$ and $1.0 \%)$ of the ten oils mixed with BDA. The variables were the radial growth rate. The test was done post-harvest immersion of the fruits of pepper for 5 minutes, the same oils used in the previous experiment, using

the highest concentration. The fungus $C$. gloeosporioides was inoculated through wounds shortly after the immersion of the fruit. The evaluations were performed daily by measuring the diameter of the colonies and injuries, taking measurements at two diametrically opposite directions. It can be observed in experiment in vitro all oils, except for babaçu oil, grape seed and almond, excellent results were inhibiting the growth of fungus. The results obtained in post-harvest was observed that only the babaçu oil was not effective in reducing lesion development of anthracnose. Relevant data were observed for oils of grape seed and almond, which had no direct effect on the fungus in vitro, but in post-harvest treatment showed good results, reducing the damage caused by C. gloeosporioides, suggesting that these oils can be used to induce resistance in pepper fruit with anthracnose.
\end{abstract}

Keywords: antifungal effect, induced resistance, anthracnose.

O fungo Colletotrichum spp. causa a doença conhecida como antracnose, que incide em uma ampla variedade de plantas. Por esse motivo o fungo possui elevado interesse econômico em plantas de diversas famílias botânicas. Dentre as famílias altamente atacadas por Colletotrichum spp. está a Solanaceae. Nesta família, o fungo ataca principalmente frutos e os sintomas da doença são caracterizados 
pela presença de lesões circulares e deprimidas, de tamanho variável, por vezes com a presença de uma massa de conídios, normalmente alaranjada. A doença se desenvolve principalmente em clima quente $\mathrm{e}$ úmido, podendo, sob tais condições, acarretar prejuízos de até $100 \%$ (7). Os sintomas podem aparecer ou intensificar-se na fase de póscolheita, o que aumenta ainda mais os prejuízos, devido ao fato de os frutos já estarem preparados para a comercialização (5).

Entre os patógenos do gênero Colletotrichum, há especialização para determinados grupos de hospedeiros. Para hortaliças solanáceas, a espécie relatada é $C$. gloeosporioides, espécie que também causa antracnose em alguns frutos como manga, mamão e abacate (23).

Sendo assim, torna-se importante o estudo dessa doença que tem causado prejuízos significativos na horticultura, a fim de buscar formas de controlá-la eficientemente. Dessa forma, várias alternativas vêm sendo sugeridas, englobando desde o controle químico, muito utilizado tradicionalmente, até o controle alternativo com substâncias obtidas a partir de produtos naturais, solução que vem sendo bem vista devido ao atual interesse mundial de utilizar produtos menos agressivos ao ambiente e que sejam mais saudáveis.

Com seriedade e persistência, vêm sendo testados, métodos alternativos para o controle de enfermidades de plantas que sejam, ao mesmo tempo, eficientes e menos agressivos à saúde humana e ao equilíbrio de ecossistemas. Encontrar a melhor forma possível de ativar os mecanismos de defesa da planta, deixando que ela própria se proteja contra os patógenos, ao invés da aplicação excessiva de defensivos químicos, certamente será a estratégia do futuro. $(1,19)$.

Muitas pesquisas vêm sendo realizadas no sentindo de tentar estabelecer um produto natural capaz de induzir certa resistência na planta contra o ataque do fungo. Dentre os diversos produtos naturais já testados, há um interesse no meio científico pela utilização de óleos essênciais extraídos de vegetais por serem produtos cuja matéria prima é facilmente encontrada na natureza e por eles se mostrarem eficientes no controle de diversos fungos em doses homeopáticas, tornando sua aplicação menos onerosa. $(8,13)$.

Inúmeros trabalhos são realizados no intuito de encontrar óleos que consigam inibir o crescimento de fungos e assim retardar o aparecimento dos sintomas da doença e que, ao mesmo tempo, consigam atingir uma grande variedade de espécies (15). Inicialmente esses trabalhos se concentram em estudos "in vitro" sobre o comportamento dos fungos em resposta a presença desses óleos essenciais em meio de cultura e, posteriormente, estudos relacionados à aplicação dessas substâncias em frutos pós colheita e em mudas vem sendo realizados com a finalidade de comparar se os bons resultados obtidos tem aplicação prática, contribuindo para a indução de resistência nessas plantas.

Nesse sentido, o presente trabalho teve como objetivo, avaliar o efeito de óleos essenciais de eucalipto (Eucaliptus spp), copaíba (Copaifera sp.), andiroba (Carapa guianensis Aubl.), babaçu (Orbignya phalerata, Mart.), coco (Cocos nucifera), neem (Azadirachta indica), semente de uva (Vitis vinifera L.), amêndoa (Prunus amygdalus Batsch), hortelã (Mentha sp) e pau rosa (Aniba rosaeodora), em diferentes concentrações sobre o desenvolvimento do fungo Colletotrichum gloeosporioides, "in vitro" e em frutos de pimenta de cheiro (Capsicum chinense) em pós colheita.

\section{MATERIAIS E MÉTODOS}

\section{Isolamento do Patógeno}

O isolado de C. gloeosporioides foi obtido de lesões típicas de antracnose de frutos de pimenta. Para todos os isolamentos foram realizados os seguintes procedimentos: após as etapas rotineiras de limpeza e desinfestação do material (9), fragmentos da região de transição, entre a lesão e os tecidos sadios foram transferidos para placas de Petri contendo meio de cultura batata-dextrose-ágar/BDA (9) e, em seguida, incubados a $25 \pm 2^{\circ} \mathrm{C}$, sob alternância luminosa fornecida por lâmpadas fluorescentes, (12h de claro/ $12 \mathrm{~h}$ de escuro). Posteriormente, fragmentos do micélio de colônias características do gênero Colletotrichum, foram transferidos para tubos contendo BDA e incubados nas mesmas condições já citadas. Após a confirmação da espécie, através da análise da seqüência de ITS do DNA ribosossomal, de acordo com Serra et al. (21), o isolado foi codificado com sigla e as culturas puras foram preservadas em tubos de ensaio contendo BDA, sob refrigeração $\left(5^{\circ} \mathrm{C}\right)$.

\section{Obtenção dos Óleos Essenciais}

O óleo de pau rosa foi obtido através da técnica de arraste por vapor d'água, realizada no laboratório de química do departamento de Tecnologia Química da Universidade Federal do Maranhão. Os demais óleos utilizados, eucalipto, copaíba, andiroba, babaçu, coco, neem, semente de uva, amêndoa e hortelã, foram obtidos comercialmente em lojas de produtos naturais.

Teste “in vitro" de Óleos Essenciais na Inibição do Crescimento de Colletotrichum gloeosporioides.

Nesse ensaio os óleos essenciais das diferentes plantas foram adicionados ao meio de cultura BDA nas seguintes concentrações $0,2 \%$; $0,4 \% ; 0,6 \% ; 0,8 \%$ e $1,0 \%$, e em seguida o meio foi vertido em placas de Petri de $9 \mathrm{~cm}$ de diâmetro. A testemunha consistia em um disco do fungo cultivado em meio BDA sem o óleo. Para avaliação das diferentes concentrações dos óleos essenciais no crescimento micelial do fungo de Colletotrichum gloeosporioides foram transferidos para o centro de cada placa de Petri um disco de meio de cultura (5 mm de diâmetro) contendo propágulos do fungo com cinco dias de idade. Em seguida, as placas foram incubadas durante sete dias, em B.O.D, em condições de alternância luminosa, a temperatura de $25 \pm 2^{\circ} \mathrm{C}$. A avaliação do crescimento micelial consistiu na medição diária do diâmetro das colônias em dois sentidos perpendiculares, com auxilio de uma régua milimetrada, obtendo-se uma média para cada repetição, de cada tratamento. Com a média dos resultados obtidos foi determinado o índice da velocidade de crescimento micelial (IVCM) (12).

O delineamento usado foi inteiramente casualizado em esquema fatorial, representado pelos óleos essenciais em diferentes concentrações (dez óleos x cinco concentração x um isolado), com quatro repetições para cada tratamento.

Os dados obtidos nesse estudo foram submetidos à análise de variância, e as médias comparadas pelo teste de Tukey a 5\% de probabilidade.

\footnotetext{
Controle de antracnose em frutos de pimenta em pós colheita com óleos essenciais.

O tratamento pós-colheita consistiu na imersão dos frutos de pimenta da variedade Dedo de Moça, por cinco minutos em soluções dos óleos essenciais preparadas na maior concentração, utilizada no experimento "in vitro", sendo adicionado a estas Tween 20 (0,02\% v/ v).

O inóculo consistiu de discos de micélio ( $5 \mathrm{~mm}$ de diâmetro) retirados de colônias do patógeno, crescida em BDA com cinco dias de idade. A inoculação foi realizada utilizando método com ferimento e depositando-se o inóculo na superfície do fruto. Em seguida, os frutos
} 
foram acondicionadas em bandejas plásticas, forradas com papel de filtro e mantidas em câmara úmida a temperatura ambiente. Para a análise do desenvolvimento da lesão, foram feitas quatro medições com intervalo de $48 \mathrm{~h}$ de uma para outra, medindo-se o tamanho da lesão.

Para a condução do experimento em pós-colheita foi utilizado o delineamento inteiramente casualizado, com dez tratamentos (os tratamentos representados pelos óleos), sendo realizadas quatro repetições por tratamento. A repetição foi constituída por frutos de pimenta, sendo 12 frutos/tratamento. Para as testemunhas repetiramse os mesmos procedimentos, porém sendo depositados somente discos de meio de cultura BDA.

Os dados obtidos nesse estudo foram submetidos à análise de variância, e as médias comparadas pelo teste de Tukey a $5 \%$ de probabilidade.

\section{RESULTADOS E DISCUSSÃO}

Teste "in vitro" de Óleos Essenciais na Inibição do Crescimento de Colletotrichum gloeosporioides.

Para os testes "in vitro" pode-se notar que o IVCM foi compatível com o crescimento micelial de C. gloeosporioides, no ultimo dia de análise, para todos os óleos utilizados, conforme apresentados nas Tabelas 1 e 2.

Foi possível observar que todos os óleos, com exceção dos óleos de babaçu, semente de uva e amêndoa, diferiram significativamente da testemunha em pelo menos uma das concentrações utilizadas, tanto para o crescimento micelial, como para velocidade de crescimento (Tabelas 1 e 2). Podemos destacar, que os óleos de copaíba, neem, hortelã e pau rosa, apresentaram os melhores resultados quanto a inibição do crescimento do fungo em todas as cinco concentrações utilizadas $(0,2 \%, 0,4 \%, 0,6 \%, 0,8 \%$ e $1,0 \%)$,como mostra a Figura 1, enquanto os óleos de andiroba, coco e eucalipto apresentaram capacidade de inibir o crescimento do fungo a medida que sua concentração foi aumentada, diferindo da testemunha a partir da concentração de $1,0 \%$ (Tabela 1). Tal fato sugere que o aumento da concentração dos outros óleos pode vir a causar um efeito inibitório no crescimento do fungo.

Diversos trabalhos vêm sendo realizados com óleos essenciais, sendo obtidos excelentes resultados. Salgado et al. (20) testando óleos extraídos de diferentes espécies de eucalipto observou inibição do crescimento micelial do fungo a medida que aumentava a concentração dessa substância. Assim como diversos outros tipos de óleos têm demonstrado capacidade de inibir o crescimento de fungos.

Ishida et al. (6) testando óleos essenciais de diferentes espécies de Copaíba, extraídos de diversas partes da planta, verificaram o potencial destes em inibir o crescimento micelial de Fusarium solani f. sp. piperis, agente causal da podridão dos pés e das raízes em plantas de pimenta-do-reino.

Silva et al. (22) avaliaram o efeito fungitóxico do óleo de neem, na inibição dos crescimento micelial e germinação de conídios de $C$. gloeospodioides isolado de folhas de seringueira e constataram que a utilização do óleo na concentração de $200 \mu \mathrm{g} / \mathrm{ml}$ inibia o crescimento micelial do fungo em $60 \%$ e que houve ainda $53,8 \%$ de inibição da germinação de conídios do patógeno.

Tabela1. Crescimento Micelial de fungo Colletotrichum gloeosporioides em presença de dez óleos essenciais em diferentes concentrações.

Crescimento Micelial* $(\mathrm{cm})$

Óleos Essenciais

\begin{tabular}{|c|c|c|c|c|c|c|c|c|c|c|c|}
\hline Conc. (\%) & Copaíba & Andiroba & Babaçu & Coco & Neem & Eucalipto & $\begin{array}{l}\text { Semente } \\
\text { de Uva }\end{array}$ & Amendoa & Hortelã & Pau Rosa & Testemunha \\
\hline 0,20 & $6.36 \mathrm{bCD}$ & $8.80 \mathrm{aAB}$ & $7.47 \mathrm{aABC}$ & $7.25 \mathrm{aBC}$ & $5.21 \mathrm{cD}$ & $8.52 \mathrm{aAB}$ & $8.59 \mathrm{aAB}$ & $8.87 \mathrm{aAB}$ & $3.34 \mathrm{bE}$ & $0.00 \mathrm{bF}$ & $9.00 \mathrm{aA}$ \\
\hline 0,60 & $4.10 \mathrm{~dB}$ & $8.04 \mathrm{abA}$ & $7.94 \mathrm{aA}$ & $8.52 \mathrm{aA}$ & $3.62 \mathrm{fB}$ & $8.29 \mathrm{abA}$ & $8.70 \mathrm{aA}$ & $8.76 \mathrm{aA}$ & $0.00 \mathrm{cC}$ & $0.00 \mathrm{bC}$ & $9.00 \mathrm{aA}$ \\
\hline 0,80 & $4.82 \mathrm{cdC}$ & $7.62 \mathrm{abB}$ & $7.79 \mathrm{aAB}$ & $8.91 \mathrm{aA}$ & $4.15 \mathrm{eC}$ & $7.37 \mathrm{bB}$ & $8.44 \mathrm{aAB}$ & $9.00 \mathrm{aA}$ & $0.00 \mathrm{cD}$ & $0.00 \mathrm{bD}$ & $9.00 \mathrm{aA}$ \\
\hline 1,00 & $4.54 \mathrm{cdD}$ & $7.31 \mathrm{bBC}$ & $8.44 \mathrm{aAB}$ & $2.37 \mathrm{bE}$ & $5.81 \mathrm{bCD}$ & $0.00 \mathrm{cF}$ & $9.00 \mathrm{aA}$ & $8.90 \mathrm{aA}$ & $0.00 \mathrm{cF}$ & $0.00 \mathrm{bF}$ & $9.00 \mathrm{aA}$ \\
\hline
\end{tabular}

*Crescimento micelial com sete dias **Letras minúsculas na vertical e maiúsculas na horizontal não diferem significativamente no teste de Tukey a $5 \%$

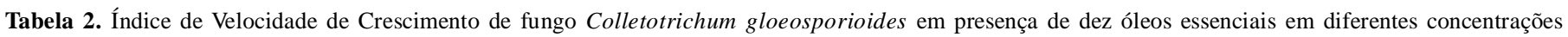
Índice de Velocidade de Crescimento*

Óleos Essenciais

\begin{tabular}{|c|c|c|c|c|c|c|c|c|c|c|c|}
\hline Conc. (\%) & Copaíba & Andiroba & Babaçu & Coco & Neem & Eucalipto & $\begin{array}{l}\text { Semente } \\
\text { de Uva }\end{array}$ & Amendoa & Hortelã & Pau Rosa & Testemunha \\
\hline 0,20 & $0.47 \mathrm{bBC}$ & $0.06 \mathrm{aAB}$ & $0.05 \mathrm{aBC}$ & $0.07 \mathrm{aAB}$ & $0.04 \mathrm{bCD}$ & $0.07 \mathrm{aA}$ & $0.07 \mathrm{abA}$ & $0.07 \mathrm{aA}$ & $0.02 \mathrm{bD}$ & $0.00 \mathrm{bE}$ & $0.07 \mathrm{aA}$ \\
\hline 0,40 & $0.04 \mathrm{bcC}$ & $0.05 \mathrm{abB}$ & $0.06 \mathrm{aB}$ & $0.07 \mathrm{aA}$ & $0.04 \mathrm{bC}$ & $0.07 \mathrm{aA}$ & $0.07 \mathrm{aA}$ & $0.06 \mathrm{aAB}$ & $0.00 \mathrm{cD}$ & $0.00 \mathrm{bD}$ & $0.07 \mathrm{aA}$ \\
\hline 0,60 & $0.03 \mathrm{cC}$ & $0.05 \mathrm{abB}$ & $0.05 \mathrm{aB}$ & $0.07 \mathrm{aA}$ & $0.03 \mathrm{cC}$ & $0.07 \mathrm{aA}$ & $0.07 \mathrm{aA}$ & $0.07 \mathrm{aA}$ & $0.00 \mathrm{cD}$ & $0.00 \mathrm{bD}$ & $0.07 \mathrm{aA}$ \\
\hline 0,80 & $0.03 \mathrm{cC}$ & $0.05 \mathrm{abB}$ & $0.05 \mathrm{aB}$ & $0.07 \mathrm{aA}$ & $0.03 \mathrm{cC}$ & $0.06 \mathrm{aAB}$ & $0.06 \mathrm{aA}$ & $0.07 \mathrm{aA}$ & $0.00 \mathrm{cD}$ & $0.00 \mathrm{bD}$ & $0.07 \mathrm{aA}$ \\
\hline 1,00 & $0.03 \mathrm{cDE}$ & $0.04 \mathrm{bBC}$ & $0.06 \mathrm{aAB}$ & $0.02 \mathrm{eE}$ & $0.04 \mathrm{bCD}$ & $0.00 \mathrm{bF}$ & $0.07 \mathrm{aA}$ & $0.07 \mathrm{aA}$ & $0.00 \mathrm{cF}$ & $0.00 \mathrm{bF}$ & $0.07 \mathrm{aA}$ \\
\hline Test. & $0.07 \mathrm{aA}$ & $0.07 \mathrm{aA}$ & $0.07 \mathrm{aA}$ & $0.07 \mathrm{aA}$ & $0.07 \mathrm{aA}$ & $0.07 \mathrm{aA}$ & $0.07 \mathrm{aA}$ & $0.07 \mathrm{aA}$ & $0.07 \mathrm{aA}$ & $0.07 \mathrm{aA}$ & $0.07 \mathrm{aA}$ \\
\hline
\end{tabular}

$*$ IVCM $=\frac{\sum(\mathrm{D}-\mathrm{Da})}{\mathrm{N}} \quad * *$ Letras minúsculas na vertical e maiúsculas na horizontal não diferem significativamente no teste de Tukey a $5 \%$. 


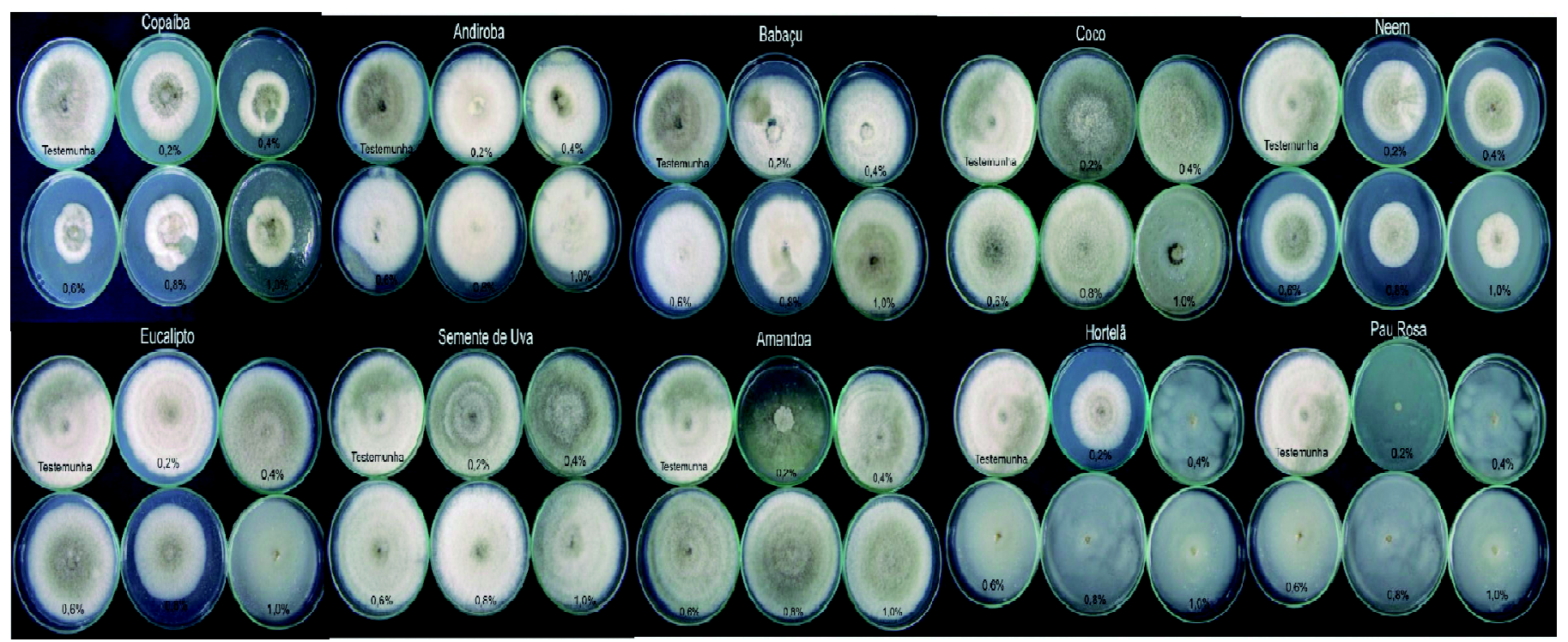

Figura 1. Crescimento micelial de Colletotrichum gloeosporioides, obtido de pimenta, com sete dias de idade, em meio de cultura BDA com a adição dos diferentes óleos essenciais, em cinco concentrações.

O teste in vitro do potencial inibitório de diferentes óleos essenciais, dentre estes o óleo de hortelã, sobre o crescimento micelial de C. gloeosporioides isolado de frutos de mamão, indicou o elevado potencial do referido óleo em impedir que o fungo se desenvolvesse sob condições artificiais (3).

Sousa Junior et al. (21) verificou inibição de $100 \%$ de germinação de esporos do fungo Colletotrichum gloeosporioides na presença dos óleos essenciais testados (alecrim-pimenta, alfavaca-cravo, capimsanto, cidrão e goiaba). Costa et al. (4) utilizando óleos essenciais de condimentos (orégano, alecrim, manjericão, menta e cebola) verificou a inibição do crescimento de diversos fungos (Aspergillus niger, A. flavus, A. ochraceus, Fusarium sp.) a medida que aumentava a concentração desses óleos.

Pinto et al. (16), ao utilizarem óleo essencial de cravo da índia e tomilho em três concentrações $(25 \mathrm{uL} / \mathrm{L}, 50 \mathrm{uL} / \mathrm{L}$ e $75 \mathrm{uL} / \mathrm{L})$ para controlar o fungo Colletotrichum gloeosporioides isolado da manga, verificaram inibição de $100 \%$ de crescimento do fungo para o óleo de cravo da índia em todas as concentrações e inibição do crescimento no óleo de tomilho a medida que a concentração desse óleo era aumentada.

Pereira et al. (14), utilizando seis concentrações de óleo de neem $(0 \%, 2 \%, 4 \%, 6 \%, 8 \%$ e $10 \%)$ com o intuito de inibir o crescimento micelial e a produção de conídios de Fusarium oxysporum f. sp. vasinfectum, observou que a medida que a concentração era aumentada, maior era a inibição do crescimento micelial e da produção de conídios.

No entanto, nem todos os óleos essenciais funcionam como inibidores diretos de fungos, ou seja, não possuem efeito fungitóxico ou fungistático. Podendo seu efeito ser observado diretamente na planta ou no fruto, a medida que retarda o aparecimento dos sintomas da doença (18).

Dessa forma, a não inibição do crescimento do fungo quando na presença dos óleos de babaçu, semente de uva e amêndoa, também pode ser explicado pelo fato de que esses óleos não apresentaram efeito fungitóxico. Sendo assim, quando um produto não possui ação fungicida, mas consegue agir na planta de outra forma, ele pode então ser classificado como indutor de resistência. (17).

Controle de antracnose em frutos de pimenta em pós-colheita com óleos essenciais.
Os resultados observados para o controle em pós-colheita, utilizando-se a concentração de $1 \%$, mostraram eficiência dos óleos essenciais em inibir o desenvolvimento da lesão de antracnose, a partir do sexto dia, para todos os óleos utilizados, com exceção do óleo de babaçu (Figura 2).

As menores lesões nos frutos foram observadas com os óleos de neem, de semente de uva, de hortelã e de pau rosa, conforme mostra a Figura 3.

Os óleos de pau rosa, hortelã e copaíba, apesar de apresentar grande inibição do crescimento fúngico, inibindo em alguns frutos $100 \%$ o crescimento de C. gloeosporioides no fruto de pimenteira, mudaram a coloração do produto, o que, em termos comerciais, poderia prejudicar a venda.

Tendo em vista os excelentes resultados obtidos, tanto "in vitro" como em pós-colheita, é de grande valia a aplicação de novos testes utilizando concentrações mais baixas do produto, ou diminuir o tempo de imersão dos frutos no óleo. Além do efeito antifúngico do óleo de pau rosa, este apresenta ação antibacteriana. Segundo Nascimento (10). Sendo assim, sugere-se que o óleo essencial de pau rosa tem efeito inespecífico no controle de fitopatógenos,
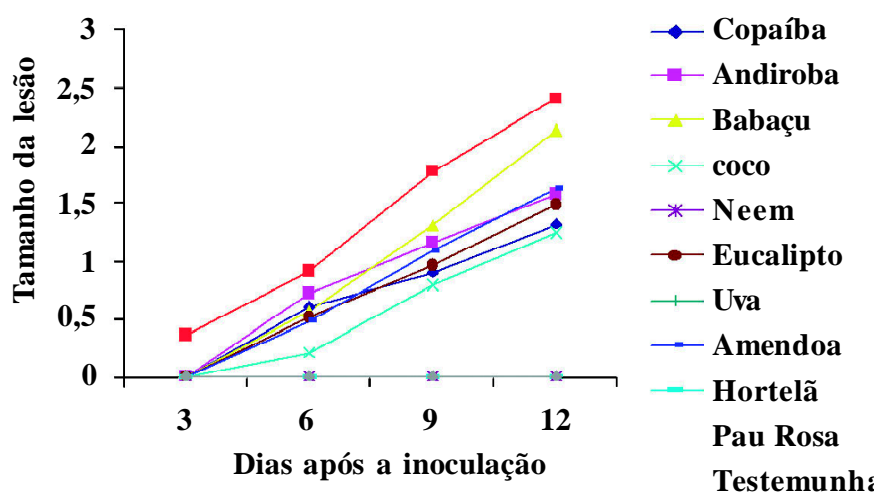

Figura 2. Tamanho da lesão causada por Colletotrichum gloeosporioides em frutos de pimenta, tratados com diferentes óleos essenciais, 12 dias após a inoculação. 


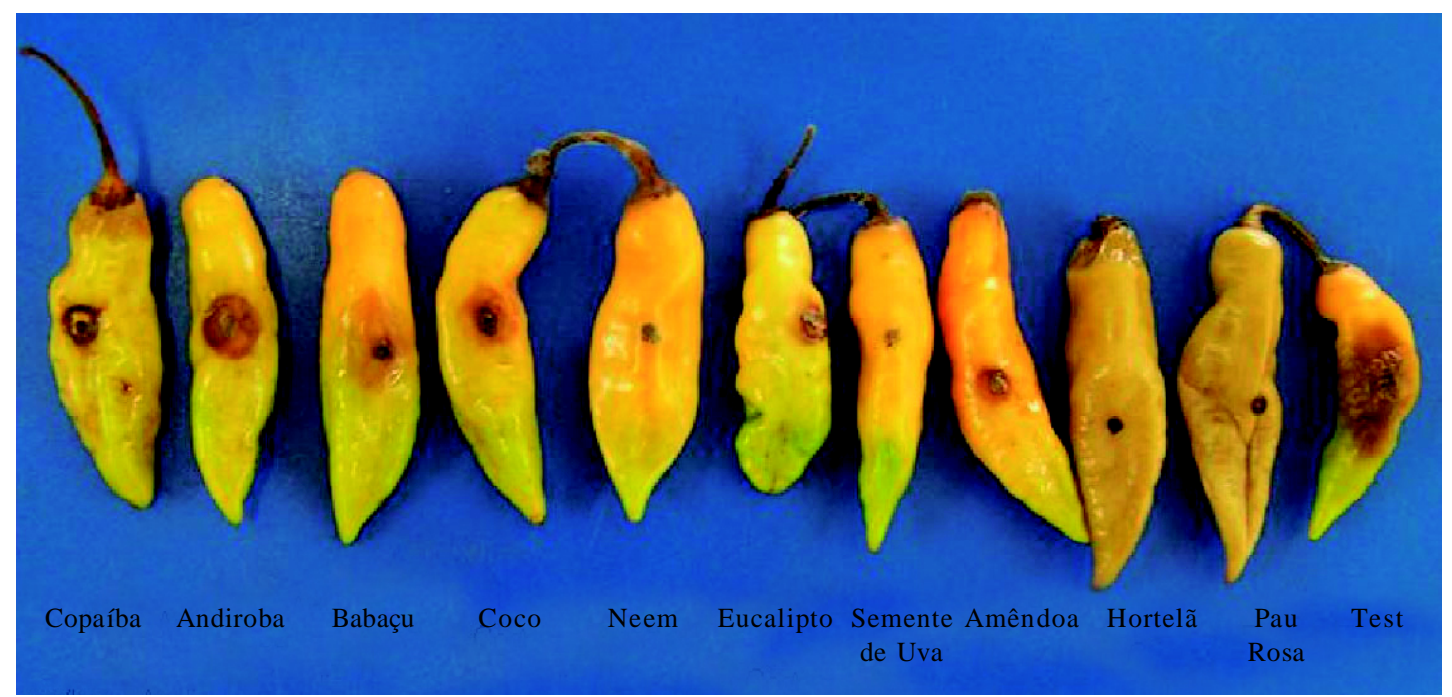

Figura 3. Lesões em frutos de pimentas inoculadas com Colletotrichum gloeosporioides e tratados com 10 óleos essenciais, após 12 dias de inoculação.

característica altamente desejável para os indutores naturais de resistência.

As pimentas tratadas com o óleo de semente de uva apresentaram grande inibição do crescimento do fungo em pós-colheita, e ainda mantiveram suas características fisiológicas como textura e coloração inalteradas, mesmo doze dias após a inoculação do fungo. Considerando que o óleo de semente de uva não apresentou resultados relevantes na inibição do fungo "in vitro", pode-se sugerir que este óleo é capaz de ativar mecanismos de resistência em frutos de pimenta para o controle de C. gloeosporioides. Da mesma forma, destaca-se o óleo de amêndoa que apresentou excelente efeito sobre a antracnose em frutos de pimenta.

Os óleos de coco, de eucalipto e de neem também mostraram inibição no desenvolvimento da lesão provocada pelo fungo. Estes resultados são compatíveis com os observados por Baldin et al. (2), no controle da podridão amarga da maçã, provocada pelo fruto Colletotrichum gloeosporioides, com a utilização do óleo de soja em quatro concentrações $(0 \mathrm{~mL} / \mathrm{L}, 1 \mathrm{~mL} / \mathrm{L}, 2 \mathrm{~mL} / \mathrm{L}, 4 \mathrm{~mL} / \mathrm{L})$, observando redução no tamanho da lesão a partir da concentração de $1 \mathrm{~mL} / \mathrm{L}$. Oliveira et al. (11), com a utilização dos óleos essenciais de alecrim pimenta e cravo-da-índia, em quatro concentrações $(0 \mathrm{uL} / \mathrm{L}, 25 \mathrm{uL} / \mathrm{L}$, 50uL/L e $75 \mathrm{uL} / \mathrm{L}$ ) no controle de Fusarium pallidoroseum em melões, observaram inibição do crescimento do fungo a partir da concentração de $25 \mathrm{uL} / \mathrm{L}$.

Com os resultados obtidos no presente trabalho foi possível observar que o uso de óleos essenciais no controle de antracnose em pimenta na pós-colheita pode ser uma alternativa viável e sustentável para o produtor.

\section{REFERÊNCIAS BIBLIOGRÁFICAS}

1. Akiba, F.; Carmo, M.G.F.; Ribeiro, R.L.D. As doenças infecciosas das lavouras dentro de uma visão agroecológica. Ação Ambiental, Viçosa, MG, v. 2, n. 5, p. 30-33, 1999

2. Baldin, I.; Cavallin, I.C.; Leite, C.D. Botelho, R.V.; DallemoleGiaretta, R.; Faria, C.M.D.R. Óleo vegetal no controle da podridão amarga da maçã em pós- colheita. Tropical Plant Pathology, Lavras, v.35, Suplemento, p.S25, 2010.

3. Carnelossi, P.R.; Schuwan-Estrada, K.R.F.; Cruz, M.E.S.; Itako,
A.T.; Mesquini, R.M. Óleos essenciais no controle pós-colheita de Colletotrichum gloeosporioides em mamão. Revista Brasileira de Plantas Medicinais, Botucatu, v.11, n.4, p.399-406, 2009.

4. Costa, R.V.; Casela, C.R.; Zambolim, L.; Ferreira, A. S. A Antracnose do Sorgo. Fitopatologia Brasileira. Brasília, v. 28, p. $345-354,2003$.

5. Fernandes, M.C.A.; Santos, A.S.; Ribeiro, L.R.D. Adaptação patogênica de isolados de Colletotrichum gloeosporioides obtidos de frutos de jiloeiro, pimentão e berinjela. Summa Phytopathologica, Botucatu, v. 28, n. 4, p. 325-330, 2002.

6. Ishida, A.K.N.; Amaral, M.A.C.M.; Gurgel, E.S.C.; Tremacoldi, C.R.; Sousa Filho, A.P. Atividade antifúngica de óleos essenciais de espécies de Copaifera sobre Fusarium solani f. sp. piperis Albuquerque. In: Congresso Brasileiro de Defensivos Agrícolas Naturais, 6., 2008, Belém. Anais. Belém: Embrapa Amazônia Oriental, 2008. p.47.

7. Lopes, C. A.; Ávila, A. C. Doenças do pimentão: diagnose e controle. Brasília, DF: Embrapa Hortaliças, 2003. 96 p.

8. Melo, R.M.C.A; Melo Filho, P.A.; Câmara, M.P.S.; Câmara, C.A.G; Santos, R.C. Prospecção de óleos vegetais para controle da ramulose do algodoeiro. In: Congresso Brasileiro do Algodão, 7. 2009, Foz do Iguaçu. Anais. Campina Grande: Embrapa Algodão, 2009, p.1021-1027.

9. Menezes, M.; Assis, S.M.P. Guia prático para fungos fitopatogênicos. 2. ed. Recife: Imprensa Universitária, UFRPE, 2004.

10. Nascimento, A.R.; Carvalho, E.P.; Furtado-Neto, A.M.A.A.; Martins, A.G.L.A.; Vieira, R.H.S.F. Atividade antibacteriana de óleos essenciais Frente a bactérias isoladas de sururu, Mytella falcata. Arquivos Ciência do Mar, Fortaleza, v. 40, n. 2, p.47-54, 2007.

11. Oliveira, E.S.; Lima, I.B.; Pessoa, M.N.G.; Santos, A.B. Efeito de óleos vegetais no controle em pós-colheita de Fusarium pallidoroseum em melão. Tropical Plant Pathology. Lavras, v.35, Suplemento, p.S32, 2010.

12. Oliveira, J.A. Efeito do tratamento fungicida em sementes e no controle de tombamento de plântulas de pepino ( $\mathrm{Cucu}$ mis sativus L.) e pimentão (Capsicum annum L.). 1991. 111p. Dissertação (Mestrado em Agronomia / Fitossanidade) - Universidade Federal de Lavras, Lavras, MG.

13. Penteado, S.R. Defensivos alternativos e naturais para uma agricultura saudável. Campinas: s.n. 1999. 79 p.

14. Pereira, P.S.X.; Araújo, D.V.; Mainardi, J.T.; Porfirio, B.F. Romano Júnior, J. Efeito de óleo de Nim no crescimento micelial e produção de conídio de Fusarium oxysporum f.sp. vasinfectum. Tropical Plant Pathology. Lavras, v.35, Suplemento, p.S12, 
2010.

15. Pimentel, F.A.; Cardoso, M.G.; Batista, L.R.; Guimarães, L.G.L.; Silva, D.M. Ação fungitóxica do óleo essencial de Tanaecium nocturnum (Barb. Rodr.) Bur. e K. Shum sobre o Aspergillus flavus isolado da castanha-do-Brasil (Bertholletia excelsa). Acta Amazônica, Belém, v. 40, n. 1, p. 213-220, 2010.

16. Pinto, F.A.M.; Reis, R.M.; Martins-Maia, F.G.; Dias, I.E.; Armesto, C.; Abreu, M.S. efeito fungitóxico de óleos essenciais sobre Colletotrichum gloeosporioides, isolados de frutos de mangueira. Tropical Plant Pathology. Lavras, MG, v. 40, n. 12, p. $213-$ $220,2010$.

17. Resende, M.L.V.; Norjosa, G.B.A; Cavalcanti, L.S.; Agrilar, M.A.G.; Silva, L.H.L.P.; Perez, J.O.; Andrade, G.C.G.; Carvalho, G.A.; Castro, R.H. Induction of resistance in cocoa against Crinipellis perniciosa and Verticillium dahliae by acibenzolar-S-methyl (ASM). Plant Pathology, London, v.5, p. 621-628. 2002.

18. Rodrigues, J.C.V.; Childers, C.C. Óleos no manejo de pragas e doenças em citros. Laranja, Cordeirópolis, v.23, n.1, p.77-100, 2002 .

19. Romeiro, R.S. Indução de resistência em plantas a patógenos. Viçosa: UFV, 1999. 45p.

20. Salgado, A.P.S; Cardoso, M.G.; Souza, P.E.; Souza, J.A.; Abreu,
C.M.P; Pinto, J.E.B.P. Avaliação da atividade fungitóxica de óleos essenciais de folhas de Eucalyptus sobre Fusarium oxysporum, Botrytis cinerea e Bipolaris sorokiniana. Ciência Agrotécnica., Lavras, v.27, n.2, p.249-254, mar./abr, 2003.

21. Serra, I.M.R.S.; Menezes, M.; Coelho, R.S.B.; Ferraz, G.M.G.; Montarroyos, A.V.V.; Martins, L.S.S.

Molecular Analysis in the Differentiation of Colletotrichum gloeosporioides Isolates from the Cashew and Mango Trees. Brazilian Archives of Biology and Technology, PR, v. 54, n.6, p.1099$1108,2011$.

22. Silva, R.A.; Pereira, R.E.A.; Nakano, M.A.S. Inibição do crescimento micelial e germinação de Colletotrichum gloeosporioides na seringueira pelo óleo de neem. Nucleus, Ituverava, v. 8, n.1, p.295-304, 2011.

23. Sousa Junior, I.T.S.; Sales, N.L.P; Martins, E.R. Efeito fungitóxico de óleos essenciais sobre Colletotrichum gloeosporioides, isolado do maracujazeiro amarelo. Revista Biotemas. Florianópolis, SC, v. 22, n.3, p.77-83, 2009.

24. Tozze-Júnior, H.J.; Mello, M.B.A.; Massola Júnior, N.S. Caracterização morfológica e fisiológica de isolados de Colletotrichum sp. Causadores de antracnose em solanáceas. Summa Phytopathologica, Botucatu, v. 32, n. 1, p. 77-79, 2006. 